\title{
Evaluation of cytocompatibility and osteoconductivity of Zr-14Nb-5Ta-1Mo alloy with MC3T3-E1 cells
}

\author{
Hiromitsu SATO ${ }^{1}$, Peng CHEN², Maki ASHIDA², Yusuke TSUTSUMl ${ }^{2,3}$, Hiroyuki HARADA ${ }^{1}$ and Takao HANAWA ${ }^{2,4}$ \\ ${ }^{1}$ Oral and Maxillofacial Surgery, Division of Oral Health Sciences, Graduate School, Tokyo Medical and Dental University (TMDU), 1-5-45 Yushima, \\ Bunkyo-ku, Tokyo 113-8510, Japan \\ ${ }^{2}$ Institute of Biomaterials and Bioengineering, Tokyo Medical and Dental University (TMDU), 2-3-10 Kanda-Surugadai, Chiyoda, Tokyo 101-0062, \\ Japan \\ ${ }^{3}$ Research Center for Structural Materials, National Institute for Materials Science (NIMS), 1-2-1 Sengen, Tsukuba, Ibaraki 305-0047, Japan \\ ${ }^{4}$ Center for Advanced Medical Engineering Research and Development, Kobe University, 1-5-1 Minatojima-minamimachi, Chuo-ku, Kobe, Hyogo \\ 650-0047, Japan \\ Corresponding author, Peng CHEN; E-mail: chen.met@tmd.ac.jp
}

\begin{abstract}
The cytocompatibility and osteoconductivity of the Zr-14Nb-5Ta-1Mo alloy were investigated using a mouse osteoblastic cell line (MC3T3-E1) to promote the application of this newly developed alloy in dental/medical treatment. The initial cell-attached morphology was visualized by fluorescent staining, and cells cultured on the Zr alloy showed similar cell adhesion behavior to cells cultured on titanium (Ti). In our 5-day proliferation investigation, similar cell numbers were obtained with both Zr alloy and Ti. These results indicate that the cytocompatibility of $\mathrm{Zr}$ alloy is similar to that of Ti. In addition, the similar results in the evaluation of alkaline phosphatase (ALP) activity and staining of deposited calcium using alizarin red S with both $\mathrm{Zr}$ alloy and Ti indicated that the osteoconductivity of the $\mathrm{Zr}$ alloy is similar to that of Ti. Our results prove the good cytocompatibility and osteoconductivity of the $\mathrm{Zr}-14 \mathrm{Nb}-5 \mathrm{Ta}-1 \mathrm{Mo}$ alloy, enabling its promotion for use in dental/medical applications.
\end{abstract}

Keywords: Zirconium alloy, Cytocompatibility, Osteogenic differentiation, Calcification

\section{INTRODUCTION}

Zirconium (Zr) alloys have recently been investigated for application in medical devices and implants. Zr and titanium (Ti) belong to the fourth group of the periodic table and have similar properties. Additionally, there is no evidence that $\mathrm{Zr}$ is toxic. The cytotoxicity of 43 metal salts was tested using two types of cell lines; Zr in the form of $\mathrm{ZrCl}_{4}$ was categorized as the safest element ${ }^{1}$. The corrosion properties, cell morphology, size, proliferation, and mitochondrial activity of MC3T3-E1 and GM7373 cells were evaluated on polished Zr. The biocompatibility range was investigated and showed following order of the investigated metals: $\mathrm{Nb}>\mathrm{Ta}, \mathrm{Ti}, \mathrm{Zr}>$ aluminum $(\mathrm{Al})>316 \mathrm{~L}$ stainless steel $(\mathrm{SS})>$ molybdenum $(\mathrm{Mo})^{2)}$. Zr showed excellent cell proliferation and a variety of alkaline phosphatase (ALP) activities in $\mathrm{SaOS}_{2}$ cells ${ }^{3)}$. The bone quality formed on $\mathrm{Zr}$ implants is at least as good as that on Ti when evaluated by the mineralization level, mineral composition, and alignment and order of mineral particles ${ }^{4}$.

Magnetic resonance imaging (MRI) that is a used medical imaging diagnostic method even in dentistry is not suitable for patients with metal implants or other non-removable metals inside their bodies, as MRI uses a strong magnetic field for scanning. Unacceptable artifacts and image defects appear around metallic devices owing to the differences in magnetic susceptibility between

Color figures can be viewed in the online issue, which is available at J-STAGE.

Received Jun 11, 2021: Accepted Nov 30, 2021

doi:10.4012/dmj.2021-169 JOI JST.JSTAGE/dmj/2021-169 metals and surrounding tissues ${ }^{5-7)}$, and the additional magnetocaloric effect precludes these patients from undergoing an MRI examination safely. However, it is difficult to alter the inherent properties of metals, for example, to reduce the magnetic susceptibility of metals for a safe MRI examination of patients who have metal implants or other non-removable metal devices. Therefore, considering the demands of dental and medical use, the development of new alloys with relatively low magnetic susceptibility is urgently needed.

The MRI artifact volume of metal is proportional to its magnetic susceptibility ${ }^{5}$. Pure $\mathrm{Zr}$ shows low magnetic susceptibility and high corrosion resistance but poor yield and tensile strength. Therefore, $\mathrm{Zr}$ alloys strengthened with solid-solution strengthening elements have been developed to decrease the artifact volume of implant devices. $\mathrm{Zr}-\mathrm{Nb}, \mathrm{Zr}-\mathrm{Ta}$, and $\mathrm{Zr}-\mathrm{Mo}$ system alloys are promising candidates because the magnetic susceptibilities of $\mathrm{Nb}, \mathrm{Mo}$, and $\mathrm{Ta}$ are low, and all these elements are safe. To date, many attempts have been made to develop new $\mathrm{Zr}$ alloys with low magnetic susceptibility, including $\mathrm{Zr}-\mathrm{Nb}^{8-10)}, \mathrm{Zr}-\mathrm{Ta}^{11,12)}, \mathrm{Zr}-\mathrm{Mo}^{13-15)}$, and $\mathrm{Zr}-\mathrm{Ag}$ alloys ${ }^{16)}$. According to these reports, $\mathrm{Zr}-14 \mathrm{Nb}$ and $\mathrm{Zr}$-1Mo alloys of decreased magnetic susceptibility have been developed. Also, as reported previously, dental casings or dental porcelains were fabricated using $\mathrm{Zr}-14 \mathrm{Nb}^{17-20)}$ and $\mathrm{Zr}-1 \mathrm{Mo}$ alloys and used in additive manufacturing to produce MRI-compatible device fimbriation by three-dimensional printing ${ }^{21-25)}$. For the $\mathrm{Zr}-14 \mathrm{Nb}$ alloy, the dental casting ability and mechanical 
properties of the cast are acceptable ${ }^{17)}$, and the bonding strength of dental porcelain is good enough ${ }^{18)}$. In addition, a white oxide layer consisting predominantly of monoclinic $\mathrm{ZrO}_{2}$, tetragonal $\mathrm{ZrO}_{2}$, and $\mathrm{Nb}_{2} \mathrm{O}_{5}$ is formed by heating that can be used for the preparation of the dental implant abutment ${ }^{26)}$.

Recently, a new beta-type $\mathrm{Zr}-14 \mathrm{Nb}-5 \mathrm{Ta}-1 \mathrm{Mo}$ alloy was prepared according to the d-electron alloy design $\operatorname{method}^{27)}$ showing magnetic susceptibility of $16.96 \times 10^{-9}$ $\mathrm{m}^{3} \mathrm{~kg}^{-1}$, approximately one-fifth that of Co-Cr-Mo alloys and one-third that of Ti alloys. Its high strength (798 $\mathrm{MPa}$ ), elongation (15\%), and low Young's modulus (61 $\mathrm{GPa}$ ) suggest great potential for dental treatment; these properties together with low magnetic susceptibility, Young's modulus, large strength, and elongation are not achieved by $\mathrm{Ti}$ alloys. It showed that the $\mathrm{Zr}-14 \mathrm{Nb}$ $5 \mathrm{Ta}-1 \mathrm{Mo}$ alloy is a promising material in dentistry and medicine.

However, the cytotoxicity and hard-tissue compatibility of the $\mathrm{Zr}-14 \mathrm{Nb}-5 \mathrm{Ta}-1 \mathrm{Mo}$ alloy are crucial factors for use in dental and medical applications. In this study, the cytocompatibility and osteoconductivity of this $\mathrm{Zr}$ alloy were investigated using a commonly used mouse preosteoblast cell line (MC3T3-E1). Our investigation into $\mathrm{Zr}-14 \mathrm{Nb}-5 \mathrm{Ta}-1 \mathrm{Mo}$ alloy properties could not only promote this hard-tissue compatibale alloy's use in dental implant fixtures, but also other potential oral treatments, including maxillofacial prostheses.

\section{MATERIALS AND METHODS}

\section{Specimen preparation}

The theoretical design of the $\mathrm{Zr}-14 \mathrm{Nb}-5 \mathrm{Ta}-1 \mathrm{Mo}$ alloy was described in a previous report ${ }^{27)}$. The starting material in the present study was an as-cast $\mathrm{Zr}$ alloy ingot with a diameter and weight of $130 \mathrm{~mm}$ and $6 \mathrm{~kg}$, respectively, which was formed by induction skull melting from weighed commercially pure $\mathrm{Zr}$ crystal bars (99.8\%), Nb chips (99.8\%), Ta chips (99.95\%), and a piece of Mo wire $(99.95 \%)$. The chemical composition of the alloy is presented in Table 1. Then, the ingot was subjected to hot forging at 1,323 $\mathrm{K}$ to form homogenized rods with a diameter of $32 \mathrm{~mm}$, and the diameter was decreased to $24 \mathrm{~mm}$ with peeling of the oxidized shell by lathe machining. Subsequently, the forged $\mathrm{Zr}-14 \mathrm{Nb}-5 \mathrm{Ta}-1 \mathrm{Mo}$ rods with $8 \mathrm{~mm}$ in diameter were processed using wire electrical discharge machining. The rod was cut into disks with a thickness of $1.5 \mathrm{~mm}$. The disk specimens were mechanically polished with a series of waterproof $\mathrm{SiC}$ abrasive papers and mirror-polished using a colloidal $\mathrm{SiO}_{2}$ suspension. After surface polishing, the specimens were rinsed two times in acetone and one time in ethanol.

In addition, a commercial-pure $\mathrm{Ti}$ rod (grade 2, diameter of $8 \mathrm{~mm}$, The Nilaco, Tokyo, Japan) was purchased and similarly surface mirror-polished and used as a control.

\section{Surface roughness evaluation}

Surface morphology and surface roughness parameters (Sa; arithmetic average height) of $\mathrm{Zr}-14 \mathrm{Nb}-5 \mathrm{Ta}-1 \mathrm{Mo}$ alloy and $\mathrm{Ti}$ specimens were measured by scanning electron microscopy (SEM; S-3400NX, Hitachi, Tokyo, Japan, not shown) and a three-dimensional measurement laser microscope (LM; LEXT OLS4000, Olympus, Tokyo, Japan), respectively. Five different areas were randomly selected for each specimen, and Sa was evaluated using bundled photo analysis software with ISO25178. Five specimens were evaluated for each metal.

Cell culture and induction of osteogenic differentiation A mouse calvaria-derived preosteoblast cell line, MC3T3-E1, was purchased from RIKEN BioResource Center (Tsukuba, Japan) and used directly. As described in previous reports ${ }^{28-30)}$, cells were cultured at $37^{\circ} \mathrm{C}$ in a humidified atmosphere of $5 \% \mathrm{CO}_{2}$ in air and maintained in a growth medium composed of the minimum essential medium Eagle with alpha modification ( $\alpha$-MEM, SigmaAldrich, St. Louis, MO, USA) supplemented with $10 \%$ fetal bovine serum and 100 U L-glutamine- penicillinstreptomycin solution (G1146, Sigma-Aldrich).

To induce osteogenic differentiation of the MC3T3-E1 cells, the growth medium was shifted with a differentiation induction medium after $100 \%$

Table 1 Concentrations of elements in Zr-14Nb-5Ta-1Mo alloy and CP Ti and the surface roughness (Sa) after polishing

\begin{tabular}{|c|c|c|c|c|c|c|c|c|c|c|c|c|}
\hline \multirow{2}{*}{ Specimen } & \multicolumn{11}{|c|}{ Concentrations of elements (wt\%) } & \multirow{2}{*}{$\begin{array}{c}\mathrm{Sa} \\
(\mu \mathrm{m})\end{array}$} \\
\hline & $\mathrm{Zr}$ & $\mathrm{Nb}$ & $\mathrm{Ta}$ & Mo & $\mathrm{Fe}$ & $\mathrm{Ti}$ & $\mathrm{C}^{*}$ & $\mathrm{O} * *$ & $\mathrm{~N}^{* * *}$ & $\mathrm{H}^{* *}$ & & \\
\hline $\begin{array}{l}\text { Zr-14Nb-5Ta-1Mo } \\
\text { alloy }\end{array}$ & Bal. & 13.5 & 4.96 & 1.00 & $<0.01$ & $<0.01$ & $<0.01$ & 0.037 & 0.014 & 0.009 & Mukai-Tanko & $0.008 \pm 0.001$ \\
\hline CP Ti (Grade 2) & - & $<0.01$ & - & - & 0.034 & Bal. & 0.004 & 0.109 & 0.004 & 0.001 & Aichi Steel & $0.012 \pm 0.001$ \\
\hline
\end{tabular}

* Determined by infrared absorption spectroscopy after combustion in a high-frequency induction furnace with a LECO CSLS-600;

** Determined by an inert gas fusion-thermal conductivity detection using LECO TCH-600;

*** Determined by an inert gas fusion-infrared absorption spectroscopy using LECO TCH-600;

Other elements were determined by inductively coupled plasma atomic emission spectroscopy (OPTIMA 8300, PerkinElmer).

The values of Sa are presented as mean \pm standard deviation values $(n=10)$. 
confluence $^{31-33)}$, and the differentiation induction medium consisted of growth medium supplemented with 50 $\mathrm{mg} \mathrm{mL} \mathrm{m}^{-1} \mathrm{~L}$-ascorbic acid (Wako, Osaka, Japan) and 2 $\mathrm{mM} \beta$-glycerophosphate (Wako). The differentiation induction medium was replaced every three days.

Before cell seeding, the $\mathrm{Zr}-14 \mathrm{Nb}-5 \mathrm{Ta}-1 \mathrm{Mo}$ alloy and $\mathrm{Ti}$ specimens were sterilized by immersion in $70 \%$ ethanol and then fully rinsed with ultra-pure water.

\section{Fluorescent staining}

The extension morphology of cells on both specimens was visualized with fluorescent staining obtained after 3,6 , and $24 \mathrm{~h}$ of cell seeding. Briefly, specimens with cell attachment were rinsed and fixed with $4 \%$ paraformaldehyde (Taab Laboratory Equipment, Reading, UK). Filamentous actin (F-actin) was stained with rhodamine phalloidin (Cytoskeleton, Denver, CO, USA). The nuclei were counterstained with 4',6diamidino-2-phenylindole (DAPI; Invitrogen, Carlsbad, CA, USA). Digital images were acquired using a fluorescence microscope (IX71; Olympus). ImageJ was used to count the number of attached cells on each surface by evaluating the number of DAPI-stained nuclei. Average data were calculated from three specimens for each testing condition, and five randomly selected locations on each specimen were detected.

\section{Cell counting}

The cellular proliferation of each specimen was evaluated by the number of attached cells on both specimens using the Cell Counting Kit-8 (CCK-8, Dojindo Laboratories, Kumamoto, Japan) for five consecutive days. The absorbance of each specimen was measured at $450 \mathrm{~nm}$ using a microplate reader (ChroMate 4300, Awareness Technology, Palm City, FL, USA) according to manufacturer's instructions ${ }^{28-30}$. In addition, a tissueculture polystyrene dish (TCPS) was employed as a control.

\section{Alkaline phosphatase (ALP) activity analysis}

ALP activity is widely used to determine the cellular potential for osteogenic differentiation ${ }^{31-34}$. In this study, the LabAssay ${ }^{\mathrm{TM}}$ ALP (Wako) was used to evaluate the ALP activity of cells with both metallic surfaces for $6,8,10,12$, and 14 days of osteogenic differentiation induction. The ALP activity of cells on each specimen was measured using ChroMate 4300 at $405 \mathrm{~nm}$ as described in our previous reports ${ }^{31,33)}$.

\section{Alizarin red $S$ staining and quantitative analysis}

To evaluate the calcification behavior of MC3T3-E1 cells cultured on both specimens, the calcium deposited by MC3T3-E1 cells was stained with alizarin red S (Sigma-Aldrich) after 14, 21, and 28 days of osteogenic differentiation induction, according to the approach reported previously ${ }^{31-35)}$. In brief, all specimens were fixed with $10 \%$ formalin (Sigma-Aldrich), fully rinsed with ultrapure water, and stained with $1 \%$ alizarin red $\mathrm{S}$ solution. After staining, all samples were rinsed to remove excess dye and dried at room temperature. The red-stained calcium deposition was photographed, and the percentage of calcified areas of the total surface was evaluated using ImageJ software.

In addition, to quantify the amount of calcium produced by MC3T3-E1 cells on both metals, the stained dye was extracted from specimens using $10 \%$ acetic acid (Sigma-Aldrich) and the absorbance was measured at $405 \mathrm{~nm}$ using ChroMate 4300, according to previous reports ${ }^{34,35)}$.

\section{Statistical analysis}

All data in this study were obtained at least three times independently and are shown as mean \pm standard deviation. The observed values were analyzed by oneway analysis of variance followed by a Student's $t$-test using KaleidaGraph4.0 (Synergy Software). Statistical significance was set at $p<0.05$.

\section{RESULTS}

\section{Surface roughness}

The surface morphology of prepared specimens was determined using SEM and LM. SEM images (not shown) revealed that, with a mirror-finishing process, both specimens possessed smooth surfaces. There was no significant difference between two specimens. In addition, Sa was automatically calculated from the observed surface morphology images by LM. Similar Sa values were observed for both specimens (Table 1), with no significant difference in Sa between the $\mathrm{Zr}-14 \mathrm{Nb}$-5Ta1Mo alloy $(12 \pm 1 \mathrm{~nm})$ and Ti specimens $(8 \pm 1 \mathrm{~nm})$.

\section{Cell adhesion}

To virtualize the cellular morphology attached to both specimens, the cellular cytoskeleton and nuclei under investigation were labeled with red and blue fluorescent dyes, respectively (Fig. 1a). Similar cellular morphologies were observed in cells cultured on both specimens after 3,6 , and $24 \mathrm{~h}$ of cell seeding. In addition, the attached cells' number was counted based on the stained nuclei. Although there was no significant difference between the attached cells' numbers of two specimens, a slightly larger cell number was detected with the $\mathrm{Zr}-14 \mathrm{Nb}-5 \mathrm{Ta}-$ 1Mo alloy compared to that with Ti, after 3 and $6 \mathrm{~h}$ of cell adhesion (Fig. 1b). Based on these results, it was shown that the cell adhesion behavior of MC3T3-E1 cells was similar in both $\mathrm{Zr}-14 \mathrm{Nb}-5 \mathrm{Ta}-1 \mathrm{Mo}$ alloy and Ti.

\section{Cell proliferation}

Cell proliferation was evaluated for 5 consecutive days (Fig. 2). The results showed that the number of adherent cells on all specimens increased with increasing culture time. Although larger cell numbers were observed for the Zr alloy compared with that for Ti and TCPS, the results of the statistical analysis showed that similar numbers of MC3T3-E1 cells were obtained from both the Zr alloy and $\mathrm{Ti}$ specimens. This result indicated that the cell proliferation behavior of MC3T3-E1 cells was similar on both Zr-14Nb-5Ta-1Mo alloy and Ti. 


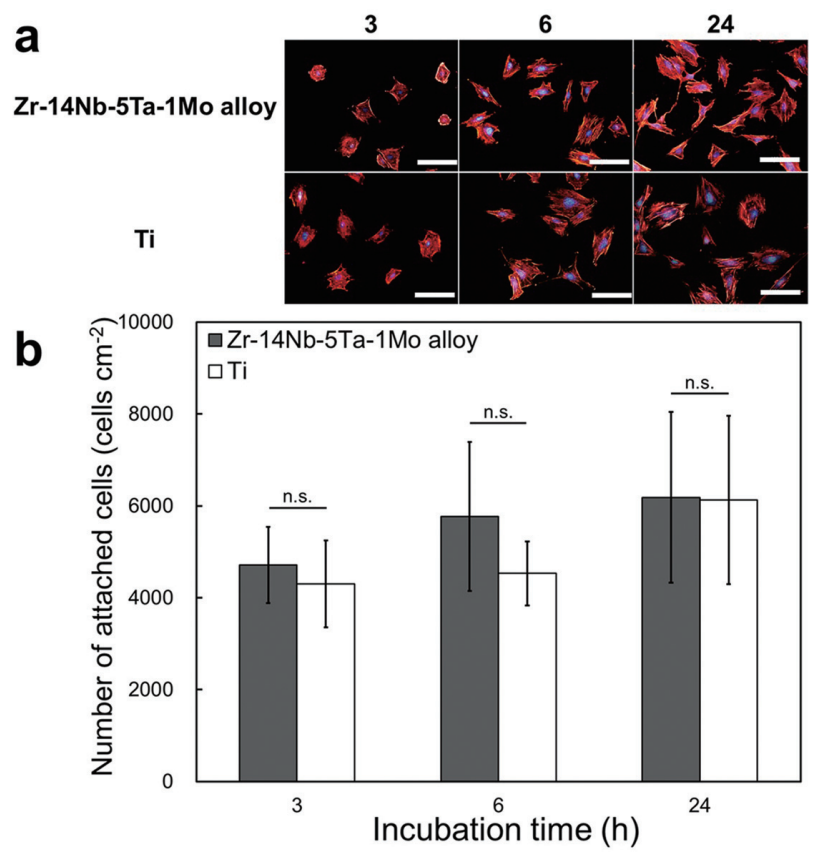

Fig. 1 Initial adhesion of MC3T3-E1 cells attached on Zr-14Nb-5Ta-1Mo alloy and Ti specimens after 3-h, 6-h, and 24-h incubations with fluorescent staining.

(a) Fluorescent photos of cellular morphologies on specimens, where nuclei and F-actin were visualized with blue and red, respectively. Scale bar: $200 \mu \mathrm{m}$.

(b) Attached cell numbers on specimens after 3-h, 6-h, and 24-h incubations.

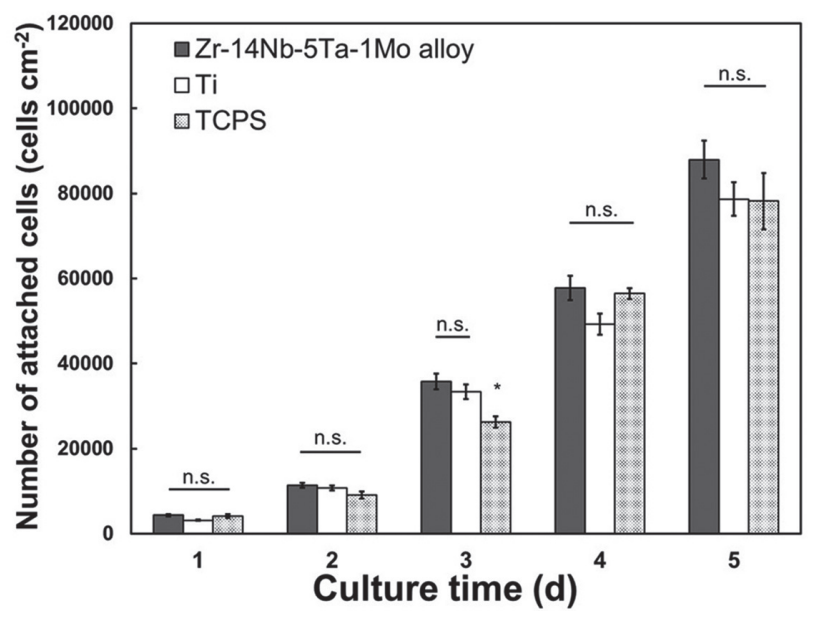

Fig. 2 Proliferation of MC3T3-E1 cultured on Zr-14Nb5 Ta-1Mo alloy, Ti, and TCPS.

The numbers of attached cells were counted by WST-8. Results were statistical analyzed, where ${ }^{*} p<0.05$; n.s., non-significant.

\section{Osteogenic differentiation}

To evaluate the potential osteoconductivity of the Zr-14Nb-5Ta-1Mo alloy, the expression level of

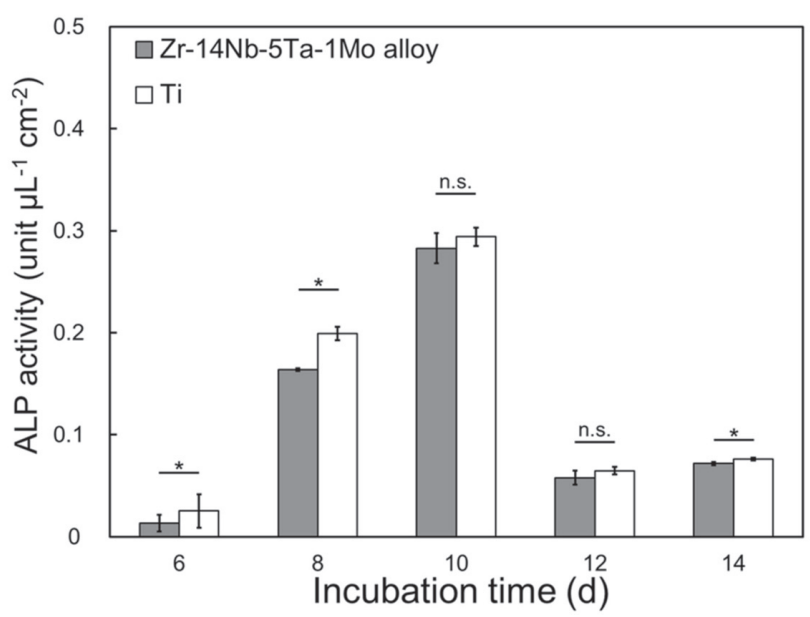

Fig. 3 Osteogenic differentiation in MC3T3-E1 cultured on Zr-14Nb-5Ta-1Mo alloy and Ti specimens through ALP activity levels detected after incubation of $6-\mathrm{d}$, 8-d, 10-d, 12-d, and 14-d differentiation induction.

intracellular ALP activity was determined, as shown in Fig. 3. A similar expression tendency of ALP activity was observed in MC3T3-E1 cells cultured on both the Zr alloy and Ti specimens. Compared with the Zr alloy, significantly higher ALP expression levels were detected in cells cultured on $\mathrm{Ti}$ specimens at an early stage, with 6-d-and 8-d differentiation induction. A similar high ALP expression level was observed in cells cultured on both specimens after a 10-d differentiation induction. With further induction of osteogenic differentiation, the expression level decreased in both specimens. This result indicated that $\mathrm{Ti}$ showed an advantage in osteoconductivity at the initial induction period, and a similar ALP activity trend and expression level was detected in MC3T3-E1 cells cultured on both specimens after 10 days.

\section{Calcification}

To evaluate the calcification of mature osteoblasts cultured on the $\mathrm{Zr}-14 \mathrm{Nb}-5 \mathrm{Ta}-1 \mathrm{Mo}$ alloy, the deposited calcium on both specimens were stained with alizarin red $\mathrm{S}$ in red color after 14, 21, and 28 days of osteogenic differentiation induction (Fig. 4). All specimens showed a red-stained area on the surfaces, and the stained area on both specimens increased with increasing induction time from 14 to 28 days. To quantitatively evaluate this result, ImageJ was used to calculate the calcified deposit area (Fig. 4b). Similar increased extracellular calcified deposit areas were obtained by cells cultured on both specimens, although a slightly larger average area value was observed in cells cultured on Ti compared with those cultured on $\mathrm{Zr}-14 \mathrm{Nb}-5 \mathrm{Ta}-1 \mathrm{Mo}$ alloy. Moreover, the total amount of deposited calcium was investigated by evaluating the absorptance of the extracted dye (Fig. 4c). A similar trend was observed in the absorptance of the extracted calcium-bonded Alizarin red $\mathrm{S}$ dye for both specimens. Although a higher value of absorptance 


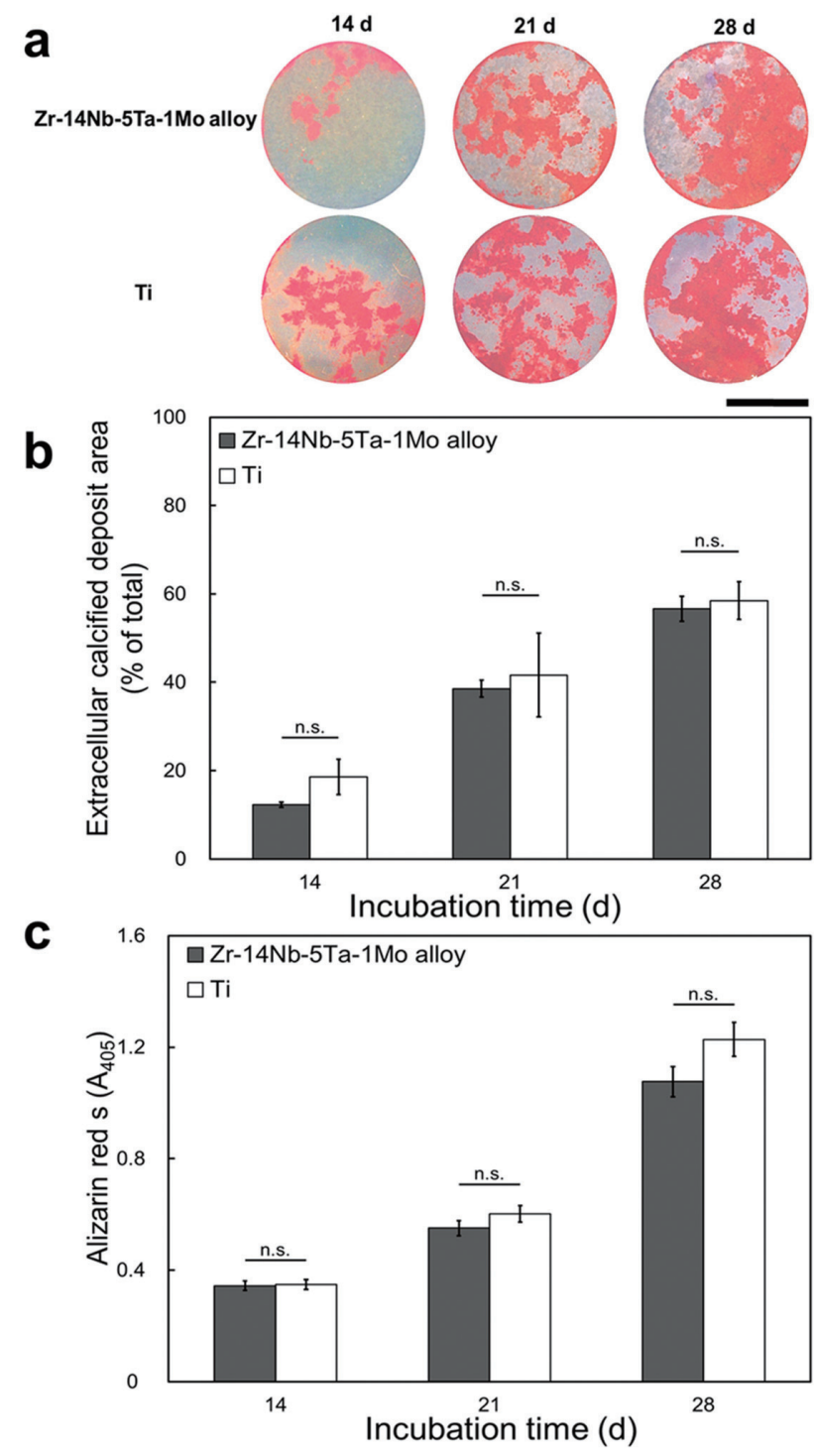

Fig. 4 Calcification of MC3T3-E1 cultured on Zr-14Nb5Ta-1Mo alloy and Ti specimens after 14-d, 21-d, and 28-d osteogenic differentiation induction stained with alizarin red $\mathrm{S}$.

(a) Photos of calcified deposits on specimens. Scale bar: $4 \mathrm{~mm}$. Histograms of quantitative analysis of calcium formation by MC3T3-E1 cultured on both specimens: (b) the proportion of the calcified area to total area of the specimens, which was calculated by ImageJ and (c) the amount of calcium deposited on specimens evaluated with the extracted stain through measuring the optical density at $405 \mathrm{~nm}$. Results were statistical analyzed, where ${ }^{*} p<0.05$; n.s., non-significant.

was observed for $\mathrm{Ti}$ compared with that of $\mathrm{Zr}-14 \mathrm{Nb}$ $5 \mathrm{Ta}-1 \mathrm{Mo}$ alloy, the results of statistical analysis showed that there was no significant difference between the two groups. This result indicated that a similar calcification behavior of MC3T3-E1 cells was obtained by both the
Zr-14Nb-5Ta-1Mo alloy and Ti specimens.

\section{DISCUSSION}

The Zr-14Nb-5Ta-1Mo alloy showed an improved balance of mechanical properties with low magnetic susceptibility $\left(16.96 \times 10^{-9} \mathrm{~m}^{3} \mathrm{~kg}^{-1}\right)$ and Young's modulus $(61 \mathrm{GPa})^{27}$, which strongly implies its potential application as implants. Although the safety or promotion of osteogenic differentiation in vitro for each additional element, niobium ${ }^{36,37)}$, tantalum ${ }^{38)}$, and molybdenum ${ }^{39,40)}$, respectively, has been reported, the lack of detailed information about the cytocompatibility and osteoconductivity of Zr-14Nb-5Ta-1Mo alloy limits its dental and medical applications.

To avoid the potential effects of the surface morphology of the specimens, mirror finishing of both specimens was carried out. Due to the difference in mechanical properties, a slightly rougher surface was determined for Zi-14Nb-5Ta-1Mo alloy specimens (12 \pm 1 $\mathrm{nm})$ compared with that of $\mathrm{Ti}$ specimens $(8 \pm 1 \mathrm{~nm})$; however, this difference was not significant (Table 1).

To evaluate the cytocompatibility of the $\mathrm{Zr}-14 \mathrm{Nb}-5 \mathrm{Ta}-$ 1Mo alloy using MC3T3-E1 cells, the initial cell adhesion and five continuous days of cellular proliferation were investigated. After 3-h of cell attachment, a similar cell morphology was observed on both the specimens. With increasing culture time, the typical cell morphology was observed on both metallic surfaces; a slightly larger cellular extension could be seen for cells on Ti compared with cells on the $\mathrm{Zr}-14 \mathrm{Nb}-5 \mathrm{Ta}-1 \mathrm{Mo}$ alloy (Fig. 1a). On the other hand, a larger attached cell number was determined for the $\mathrm{Zr}$ alloy after 3 -h and 6 -h of incubation, which suggested a satisfactory biocompatibility of the Zr alloy for initial cell attachment (Fig. 1b). After 24-h incubation, similar attached cell numbers were detected for both specimens. The above data indicated that the cell adhesion presented by the $\mathrm{Zr}$ alloy and Ti were similar, especially early, at 3 and $6 \mathrm{~h}$. On the surface of the $\mathrm{Zr}$ alloy, MC3T3-E1 cells showed equal or slightly better cell proliferation than cells cultured on Ti specimens (Fig. 2). The Zr-14Nb-5Ta-1Mo alloy was found to have good cell compatibility similar to Ti in vitro.

To evaluate the osteoconductivity of the $\mathrm{Zr}-14 \mathrm{Nb}$ 5Ta-1Mo alloy with MC3T3-E1, cells were induced to differentiate into osteoblasts, which is called osteogenesis, and mature osteoblasts induce calcium phosphate formation on the specimens, which is called calcification. Among the currently used dental implant materials, superior osseointegration of Ti and its alloys is widely known, given the promotion of osteoconductivity of pre-osteoblasts cultured on them ${ }^{41,42)}$. In addition, the cellular expression level of ALP has been recognized as an important criterion for evaluating the osteoconductivity of test specimens ${ }^{43,44)}$. After approximately one week of osteogenesis, a relatively lower level of cellular ALP activity was observed by $\mathrm{Zr}-14 \mathrm{Nb}-5 \mathrm{Ta}-1 \mathrm{Mo}$ alloy compared with that by Ti specimens (Fig. 3), which indicated a potential advantage of Ti in osteoconductivity during initial osteogenic differentiation stage, 
comparing with that displayed by $\mathrm{Zr}-14 \mathrm{Nb}-5 \mathrm{Ta}-1 \mathrm{Mo}$ alloy. Undifferentiated data were then analyzed. This slight advantage in cellular osteogenesis influences the calcification of mature osteoblasts, as shown in Fig. 4. Interestingly, through long-term observation, this advantage was not obvious, although Ti still showed a larger amount of deposited calcium on its surface after 28 days of culture (Fig. 4c). This phenomenon could be explained by the subsequent calcification occurring on the initial calcification layer during the first two weeks ${ }^{32}$. Based on these results, the $\mathrm{Zr}-14 \mathrm{Nb}-5 \mathrm{Ta}-1 \mathrm{Mo}$ alloy showed good cytocompatibility and osteoconductivity similar to Ti.

Other potential reasons why $\mathrm{Zr}-14 \mathrm{Nb}-5 \mathrm{Ta}-1 \mathrm{Mo}$ alloy displays good cytocompatibility and osteoconductivity similar to $\mathrm{Ti}$ may include the following two points: First, although the ability of pure $\mathrm{Zr}$ to form calcium phosphate is inferior to that of $\mathrm{Ti}^{45)}$, cell compatibility with the Zr alloy is as good as that of Ti due to potent corrosion resistance of the zirconium alloy, and strong immobility of the film ${ }^{46)}$. Secondly, as mentioned in the introduction and a previous report ${ }^{27)}$, during the new alloy design stage, only non-toxic elements were selected for incorporation into Zr alloys. The current experimental results confirm our concept of alloy design.

On the other point of view, we hypothesize that the similar good cytocompatibility and osteoconductivity detected with $\mathrm{Zr}$ alloys, as Ti does, benefits from their surface passive oxide film. It was reported that, compared sputter-deposited $\mathrm{Au}$, a similar cellular behaviors, including proliferation and osteogenic differentiation, was detected by cells cultured on sputter-deposited $\mathrm{Ti}$ and $\mathrm{Zr}$, where a thin titanium oxide film and zirconium oxide film were detected on the specimens, respectively ${ }^{32}$. The high expression levels of Runx2, Col1 $\alpha 1$, and Akp2 in MC3T3-E1 cells cultured on sputter-deposited Ti and $\mathrm{Zr}$ indicated a faster osteogenic differentiation and calcification. It is worth noting that the both deposited $\mathrm{Ti}$ and $\mathrm{Zr}$ through sputtering are amorphous structure. On the other hand, as an additional component, it reported in several literatures, that the cytocompatibility and osteoconductivity of the composites improved with the addition of zirconium oxide ${ }^{47-50)}$ or addition of zirconium oxide nanoparticles into nanocomposites directly ${ }^{51}$. Although the up-regulation of osteogenic genes were determined ${ }^{32,50)}$, the induction mechanisms is still not fully clear. One potential osteoconductivity of related cellular signaling pathways was thought to be the mitogen-activated protein kinase (MAPK)/extracellular signal-regulated kinases $(\mathrm{ERKs})^{52,53)}$. Among the different stimuli actives this MAPK/ERK pathway, the regulation of gene expression of $B M P 2$ and its receptors was recognized important one. It was reported that the addition of the zirconium ions could be another effective to improve the cellular cytocompatibility ${ }^{54}$. Even, it was reported that zirconium ions increased the proliferation and gene expression of BMP2 and BMP receptor and associated with increased phosphorylation of SMAD1/5 of human osteoblasts (HOBs), which indicated the zirconium ions promote the cellular proliferation and osteogenic differentiation through up-regulate the BMP/ SMAD signaling pathway ${ }^{55)}$.

The satisfactory cytocompatibility and osteoconductivity of the Zr-14Nb-5Ta-1Mo alloy will not only strongly promote the use of this hardtissue compatible alloy with relatively low magnetic susceptibility in dental implant fixtures, but also in other oral treatments, including maxillofacial prostheses. The low elastic modulus of this $\mathrm{Zr}$ alloy is thought to be another advantage supporting application in maxillofacial prosthesis plates, where the quotient force is not directly conducted to the mandible, and stress shielding will be prevented.

\section{CONCLUSIONS}

In this study, the cytocompatibility and osteoconductivity of the $\mathrm{Zr}-14 \mathrm{Nb}-5 \mathrm{Ta}-1 \mathrm{Mo}$ alloy were investigated using a mouse preosteoblast cell line, MC3T3-E1. After the mirror-finishing polishing process, a smooth surface was obtained. The visualized cellular initial extension morphology showed a similar good cell adhesion behavior of both the Zr-14Nb-5Ta-1Mo alloy and Ti. The cell proliferation investigation showed similar cell numbers on the $\mathrm{Zr}$ alloy and $\mathrm{Ti}$, indicating good cytocompatibility of the alloy, similar to Ti. In addition, the osteoconductivity of the $\mathrm{Zr}-14 \mathrm{Nb}-5 \mathrm{Ta}-1 \mathrm{Mo}$ alloy was investigated through ALP activity evaluation and alizarin red $\mathrm{S}$ staining calcification. The results showed that, although a slower osteogenic differentiation induction was observed at an early stage by cells on the $\mathrm{Zr}-14 \mathrm{Nb}-5 \mathrm{Ta}-1 \mathrm{Mo}$ alloy compared with those on $\mathrm{Ti}$, a similar good osteoconductivity of $\mathrm{Zr}$ quaternary alloy and $\mathrm{Ti}$ was observed at the following stage. Our study provides proof of the good cytocompatibility and osteoconductivity of the newly designed $\mathrm{Zr}-14 \mathrm{Nb}-5 \mathrm{Ta}-$ 1 Mo alloy; these results can enable the promotion of the application of $\mathrm{Zr}$ alloys in dental/medical treatment.

\section{ACKNOWLEDGMENTS}

This study was supported by the Japan Society for the Promotion of Science (JSPS), KAKEN, Grant Number: $15 \mathrm{H} 03018$ and 19H04464, and by The Creation of Life Innovation Materials for Interdisciplinary and International Researcher Development Project and Viable Materials Project, Ministry of Education, Culture, Sports, Science and Technology (MEXT), Japan.

\section{REFERENCES}

1) Yamamoto A, Honma R, Sumita M. Cytotoxicity evaluation of 43 metal salts using murine fibroblasts and osteoblastic cells. J Biomed Mater Res 1998; 39: 331-340.

2) Eisenbarth E, Velten D, Muller M, Thull R, Breme J. Biocompatibility of beta-stabilizing elements of titanium alloys. Biomaterials 2004; 25: 5705-5713.

3) Zhang DM, Wong CS, Wen C, Li YC. Cellular responses of osteoblast-like cells to 17 elemental metals. J Biomed Mater Res Part A 2017; 105A: 148-158.

4) Hoerth RM, Katunar MR, Sanchez AG, Orellano JC, Silvia 
M, Ceré SM, et al. A comparative study of zirconium and titanium implants in rat: Osseointegration and bone material quality. J Mater Sci Mater Med 2014; 25: 411-422.

5) Imai H, Tanaka $Y$, Nomura N, Tsutsumi $Y$, Doi H, Kanno $\mathrm{Z}$, et al. Three-dimensional quantification of susceptibility artifacts from various metals in magnetic resonance images. Acta Biomater 2013; 9: 8433-8439.

6) Imai H, Tanaka Y, Nomura N, Doi H, Tsutsumi Y, Ono T, et al. Magnetic susceptibility, artifact volume in MRI, and tensile properties of swaged $\mathrm{Zr}$-Ag composites for biomedical applications. J Mech Behav Biomed Mater 2017; 66: 152158.

7) Kawabata I, Imai H, Kanno Z, Tetsumura A, Tsutsumi Y, Doi $\mathrm{H}$, et al. Three-dimensional quantification of magnetic resonance imaging artifacts associated with shape factors. Dent Mater J 2019; 38: 638-645.

8) Kondo R, Nomura N, Suyalatu, Tsutsumi Y, Doi H, Hanawa T. Microstructure and mechanical properties of as-cast $\mathrm{Zr}-\mathrm{Nb}$ alloys. Acta Biomater 2011; 7: 4278-4284.

9) Kondo R, Shimizu R, Nomura N, Doi H, Suyalatu, Tsutsumi $\mathrm{Y}$, et al. Effect of cold rolling on the magnetic susceptibility of Zr-14Nb alloy. Acta Biomater 2013; 9: 5795-5801.

10) Kondo R, Nomura N, Doi H, Matsuinoto H, Tsutsumi $Y$, Hanawa T. Effect of heat treatment and the fabrication process on mechanical properties of $\mathrm{Zr}-14 \mathrm{Nb}$ alloy. Mater Trans 2016; 57: 2060-2064.

11) Takaku A, Tanaka Y, Takahashi S, Nomura N, Hanawa T. Effect of Ta concentration on hardness of low magnetic ZrTa alloy. Collected Abstracts of the 153th Meeting of JIM Autumn Meeting 2013; 2013 Sept. 17-19; Kanazawa, Japan. Sendai: The Japan Insititute of Metal and Materials (JIM); 2013 p. 119 (in Japanese).

12) Tanaka Y, Takaku A, Takahashi S, Nomura N, Hanawa T. Relationship between phase boundary region and elastic modulus of low magnetic Zr-Ta alloy. Collected Abstracts of the 153th Meeting of JIM Autumn Meeting 2013; 2013 Sept. 17-19; Kanazawa, Japan. Sendai: The Japan Insititute of Metal and Materials (JIM); 2013 p. 120 (in Japanese).

13) Suyalatu, Nomura N, Oya K, Tanaka Y, Kondo R, Doi H, et al. Microstructure and magnetic susceptibility of as-cast Zr-Mo alloys. Acta Biomater 2010; 6: 1033-1038.

14) Suyalatu, Kondo R, Tsutsumi Y, Doi H, Nomura N, Hanawa T. Effects of phase constitution on magnetic susceptibility and mechanical properties of Zr-rich Zr-Mo alloys. Acta Biomater 2011; 7: 4259-4266.

15) Ashida M, Morita M, Tsutsumi Y, Nomura N, Doi H, Chen $\mathrm{P}$, et al. Effects of cold swaging on mechanical properties and magnetic susceptibility of the $\mathrm{Zr}-1 \mathrm{Mo}$ alloy. Metals (Basel) 2018; 8: 454.

16) Seki I, Umetsu RY, Xie GQ, Nomura N, Wang XM, Hanawa T. Cooling rate and composition dependences of magnetic susceptibility for Zr54-xCu30+xAl8Ag8 glassy alloys. Mater Trans 2013; 54: 1356-1360.

17) Kajima Y, Doi H, Takaichi A, Hanawa T, Wakabayashi N. Surface characteristics and castability of $\mathrm{Zr}-14 \mathrm{Nb}$ alloy dental castings. Dent Mater J 2014; 33: 631-637.

18) Kajima Y, Takaichi A, Yasue T, Doi H, Takahashi H, Hanawa $\mathrm{T}$, et al. Evaluation of the shear bond strength of dental porcelain and the low magnetic susceptibility $\mathrm{Zr}-14 \mathrm{Nb}$ alloy. J Mech Behav Biomed Mater 2016; 53: 131-141.

19) Kajima $Y$, Takaichi $A$, Nakamoto $T$, Kimura $T$, Kittikundecha $\mathrm{N}$, Tsutsumi $\mathrm{Y}$, et al. Effect of adding support structures for overhanging part on fatigue strength in selective laser melting. J Mech Behav Biomed Mater 2018; 78: 1-9.

20) Kittikundecha N, Kajima Y, Takaichi A, Cho HHW, Htat HL, Doi $\mathrm{H}$, et al. Fatigue properties of removable partial denture clasps fabricated by selective laser melting followed by heat treatment. J Mech Behav Biomed Mater 2019; 98: 79-89.

21) Sun XH, Zhou WW, Kikuchi K, Nomura N, Kawasaki A, Doi
$\mathrm{H}$, et al. Fabrication and characterization of a low magnetic Zr-1Mo alloy by powder bed fusion using a fiber laser. Metals (Basel) 2017; 7: 501.

22) Sun XH, Liu DB, Chen MF, Zhou WW, Nomura N, Hanawa T. Hot isostatic pressing of MRI compatible $\mathrm{Zr}$-1Mo components manufactured by laser powder bed fusion. Mater Charact 2020; 169: 110657.

23) Sun XH, Liu DB, Zhou WW, Nomura N, Tsutsumi Y, Hanawa T. Effects of process parameters on the mechanical properties of additively manufactured $\mathrm{Zr}$-1Mo alloy builds. J Mech Behav Biomed Mater 2020; 104: 103655.

24) Sun XH, Liu DB, Chen MF, Zhou WW, Nomura N, Hanawa T. Combination of hot isostatic pressing and subsequent heat treatment for additively manufactured $\mathrm{Zr}$-1Mo components. Mater Lett 2021; 285: 129123.

25) Sun XH, Liu DB, Chen MF, Zhou WW, Nomura N, Hanawa T. Influence of annealing treatment on the microstructure, mechanical performance and magnetic susceptibility of low magnetic Zr-1Mo parts manufactured via laser additive manufacturing. Mater Sci Eng A 2021; 804: 140740.

26) Yu M, Doi H, Tsutsumi Y, Chen P, Ashida M, Kasugai S, et $a l$. Formation of white oxide layer on $\mathrm{Zr}-14 \mathrm{Nb}$ alloy using thermal treatment. Dent Mater J 2014; 33: 490-498.

27) Ashida M, Tsutsumi Y, Homma K, Chen P, Shimojo M, Hanawa T. Design of zirconium quaternary system alloys and their properties. Mater Trans 2020; 61: 776-781.

28) Chen P, Ashida M, Doi H, Tsutsumi Y, Horita Z, Hanawa T. Cytocompatibility of Ti-6Al-7Nb through high-pressure torsion processing. Mater Trans 2016; 57: 2020-2025.

29) Chen $P$, Miyake M, Tsukamoto M, Tsutsumi $Y$, Hanawa T. Response of preosteoblasts to titanium with periodic micro/ nanometer scale grooves produced by femtosecond laser irradiation. J Biomed Mater Res A 2017; 105: 3456-3464.

30) Chen P, Liu HH, Niinomi M, Horita Z, Fujii H, Hanawa T. Fatigue Property and cytocompatibility of a biomedical Co-Cr-Mo alloy subjected to a high pressure torsion and a subsequent short time annealing. Mater Trans 2020; 61: 361367.

31) Sato M, Chen P, Tsutsumi Y, Shiota M, Hanawa T, Kasugal S. Effect of strontium ions on calcification of preosteoblasts cultured on porous calcium- and phosphate-containing titanium oxide layers formed by micro-arc oxidation. Dent Mater J 2016; 35: 627-634.

32) Chen P, Nagai A, Tsutsumi Y, Ashida M, Doi H, Hanawa T. Differences in the calcification of preosteoblast cultured on sputter-deposited titanium, zirconium, and gold. J Biomed Mater Res A 2016; 104: 639-651.

33) Umezawa T, Chen P, Tsutsumi Y, Doi H, Ashida M, Suzuki $\mathrm{S}$, et al. Calcification of MC3T3-E1 cells on titanium and zirconium. Dent Mater J 2015; 34: 713-718.

34) Chen P, Aso T, Sasaki R, Ashida M, Tsutsumi Y, Doi H, et al. Adhesion and differentiation behaviors of mesenchymal stem cells on titanium with micrometer and nanometer-scale grid patterns produced by femtosecond laser irradiation. J Biomed Mater Res A 2018; 106: 2735-2743.

35) Chen P, Aso T, Sasaki R, Tsutsumi Y, Ashida M, Doi H, et $a l$. Micron/submicron hybrid topography of titanium surfaces influences adhesion and differentiation behaviors of the mesenchymal stem cells. J Biomed Nanotechnol 2017; 13: 324-336.

36) Antonini LM, Menezes TL, Dos Santos AG Jr, Takimi AS, Villarinho DJ, Dos Santos BP, et al. Osteogenic differentiation of bone marrow-derived mesenchymal stem cells on anodized niobium surface. J Mater Sci Mater Med 2019; 30: 104.

37) Torres-Sanchez C, Norrito M, Wang J, Bell H, Zani L, Conway PP. Physico-chemical characterisation of Ti-Nb-Sn alloys surfaces and their osteogenic properties. Surf Coat Tech 2020; 403: 126439.

38) Park C, Park S, Kim J, Han A, Ahn S, Min SK, et al. Enhanced 
endothelial cell activity induced by incorporation of nanothick tantalum layer in artificial vascular grafts. Appl Surf Sci 2020; 508: 144801.

39) Yang TY, Yen CC, Lee KI, Su CC, Yang CY, Wu CC, et al. Molybdenum induces pancreatic beta-cell dysfunction and apoptosis via interdependent of JNK and AMPK activationregulated mitochondria-dependent and ER stress-triggered pathways. Toxicol Appl Pharmacol 2016; 294: 54-64.

40) Zhang XD, Nie JH, Yang XX, Liu ZR, Guo WB, Qiu JC, et al. Nanostructured molybdenum disulfide biointerface for adhesion and osteogenic differentiation of mesenchymal stem cells. Appl Mater Today 2018; 10: 164-172.

41) Branemark PI. Osseointegration and its experimental background. J Prosthet Dent 1983; 50: 399-410.

42) Bosshardt DD, Chappuis V, Buser D. Osseointegration of titanium, titanium alloy and zirconia dental implants: current knowledge and open questions. Periodontol 2000 2017; 73: 22-40.

43) hyte MP, Vrabel LA. Infantile hypophosphatasia fibroblasts proliferate normally in culture: evidence against a role for alkaline phosphatase (tissue nonspecific isoenzyme) in the regulation of cell growth and differentiation. Calcif Tissue Int 1987; 40: 1-7.

44) Sugawara Y, Suzuki K, Koshikawa M, Ando M, Iida J. Necessity of enzymatic activity of alkaline phosphatase for mineralization of osteoblastic cells. Jpn J Pharmacol 2002; 88: 262-269.

45) Tsutsumi Y, Nishimura D, Doi H, Nomura N, Hanawa T. Difference in surface reactions between titanium and zirconium in Hanks' solution to elucidate mechanism of calcium phosphate formation on titanium using XPS and cathodic polarization. Mater Sci Eng C 2009; 29: 1702-1708.

46) Tsutsumi Y. Corrosion resistance of Zr as metallic biomaterials. Zairyo-to-Kankyo 2014; 63: 360-364 (in Japanese).

47) Ochoa-Rodriguez VM, Tanomaru-Filho M, Rodrigues EM, Guerreiro-Tanomaru JM, Spin-Neto R, Faria G. Addition of zirconium oxide to Biodentine increases radiopacity and does not alter its physicochemical and biological properties. J Appl
Oral Sci. 2019; 27: e20180429.

48) Smieszek A, Szydlarska J, Mucha A, Chrapiec M, Marycz K. Enhanced cytocompatibility and osteoinductive properties of sol-gel-derived silica/zirconium dioxide coatings by metformin functionalization. J Biomater Appl 2017; 32: 570-86.

49) Bhowmick A, Jana P, Pramanik N, Mitra T, Banerjee SL, Gnanamani A, et al. Multifunctional zirconium oxide doped chitosan based hybrid nanocomposites as bone tissue engineering materials. Carbohydr Polym 2016; 151: 879-888.

50) Seweryn A, Pielok A, Lawniczak-Jablonska K, Pietruszka R, Marcinkowska K, Sikora M, et al. Zirconium oxide thin films obtained by atomic layer deposition technology abolish the anti-osteogenic effect resulting from miR-21 inhibition in the pre-osteoblastic MC3T3 cell line. Int J Nanomedicine 2020; 15: 1595-1610.

51) Bhowmick A, Pramanik N, Jana P, Mitra T, Gnanamani A, Das M, et al. Development of bone-like zirconium oxide nanoceramic modified chitosan based porous nanocomposites for biomedical application. Int J Biol Macromol 2017; 95: 348356.

52) Lu ZL, Zreiqat H. The osteoconductivity of biomaterials is regulated by bone morphogenetic protein 2 autocrine loop involving alpha 2 beta 1 Integrin and mitogen-activated protein kinase/extracellular related kinase signaling pathways. Tissue Eng 2010; 16: 3075-3084.

53) $\mathrm{Lu} \mathrm{ZF}$, Zreiqat H. Beta-tricalcium phosphate exerts osteoconductivity through alpha 2 beta 1 integrin and downstream MAPK/ERK signaling pathway. Biochem Biophys Res Commun 2010; 394 :323-239.

54) Cheng M, Qiao Y, Wang Q, Qin H, Zhang X, Liu X. Dual ions implantation of zirconium and nitrogen into magnesium alloys for enhanced corrosion resistance, antimicrobial activity and biocompatibility. Colloids Surf B Biointerfaces 2016; 148: 200-210.

55) Chen Y, Roohani-Esfahani SI, Lu Z, Zreiqat H, Dunstan CR. Zirconium ions up-regulate the BMP/SMAD signaling pathway and promote the proliferation and differentiation of human osteoblasts. PLoS One. 2015; 10: e0113426. 